\title{
A Study of the Dynamic Response of Carbon Fiber Reinforced Epoxy (CFRE) Prepregs for Musical Instrument Manufacturing
}

\author{
Manuel Ibáñez-Arnal *D, Luis Doménech-Ballester and Fernando Sánchez-López \\ Department of Mathematics, Physics and Technology Sciences. University CEU Cardenal Herrera, CEU \\ Universities, Avda. Seminario s/n, 46113 Moncada, Spain; luis.domenech@uchceu.es (L.D.-B.); \\ fernando.sanchez@uchceu.es (F.S.-L.) \\ * Correspondence: manuel.ibanez@uchceu.es
}

Received: 23 September 2019; Accepted: 28 October 2019; Published: 30 October 2019

check for updates

\begin{abstract}
Composite materials are presented in a wide variety of industrial sectors as an alternative to traditionally used materials. In recent years, a new sector has increasingly used these kinds of materials: the manufacture of musical instruments. Resonances of different elements that make up the geometries of musical instruments are commonly used with the aim of enhancing aspects of the timbre. These are sensitive to the mechanical characteristics of the material, so it is important to guarantee the properties of the composite. To do this, it is not uncommon to use pre-impregnated fibers (prepregs) which allow fine control of final volumetric fractions of the composite. Autoclaving is a high-quality process used to guarantee the desired mechanical properties in a composite, reducing porosity and avoiding delamination, but significantly raising production costs. On the contrary, manufacture without autoclaving increases competitiveness by eliminating the costs associated with autoclave production. In this paper, differences in dynamic behavior are evaluated under free conditions of different Carbon Fiber Reinforced Epoxy (CFRE) prepreg boards, processed by autoclave and out-of-autoclave. The results of the complex module are presented according to the frequency, quantifying the variations in the vibratory behavior of the material due to the change of processing.
\end{abstract}

Keywords: autoclave; out-of-autoclave; vacuum-bag-only; processing; CFRE; plates; modal; dynamic; musical instruments

\section{Introduction}

Interest in characterizing the elastic and damping properties of composites is increasing as more and more industrial sectors use these materials in very different applications. Among these, the most established sectors include the automotive, aerospace, and renewable energy industries [1-5]. However, in recent years, this has expanded to include other types of products, such as musical instruments.

In this expanding new sector, the modal and transient behavior of different structures has been studied. Commonly, in musical instruments resonances are usually sought to enhance the sound pressure levels obtained for different resonances, modifying the timbre and the qualitative aspects of the resulting sound. Research is particularly extensive in the chordophone family, particularly in the case of classical guitars [6-12], electric guitars [13,14], or the string family of instruments [15-19]. We also find studies linked to percussive chordophones such as the piano [20-22] and, though scarcer, those dedicated to membranophones [23-25]. Figure 1 shows some examples. 


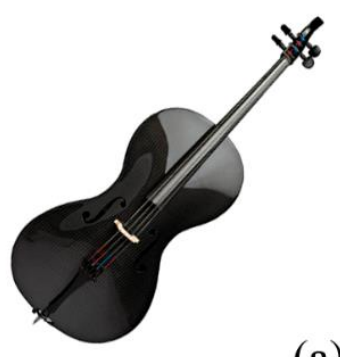

(a)

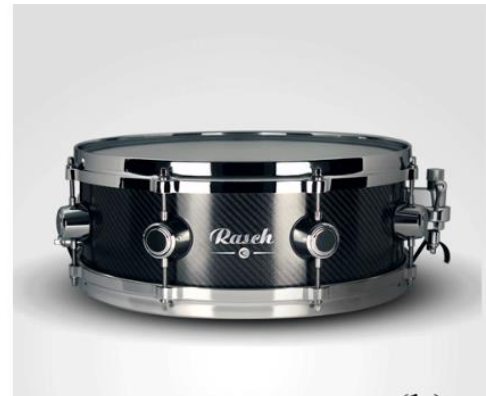

(b)

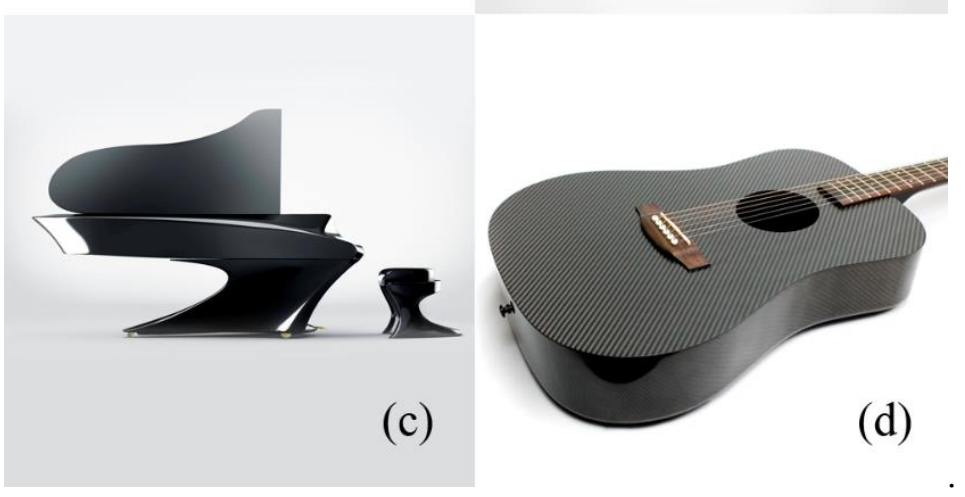

Figure 1. Some musical instruments made of carbon fiber reinforced with epoxy (CFRE): (a) Luis and Clark violoncello [26], (b) Rasch snare drum [27], (c) Boganyi piano [28], and (d) Klos carbon fiber guitar [29].

Composite materials use polymer matrices in their manufacture, so they have viscoelastic behavior. Viscoelasticity is the property of materials that exhibit both viscous and elastic characteristics when undergoing deformation. For the study of this type of material, we express the module in its complex form, as shown by Equation (1) [30]

$$
E^{*}=E^{\prime}+j E^{\prime \prime}
$$

where the real part $\left(E^{\prime}\right)$ is the storage modulus, and the imaginary part $\left(E^{\prime \prime}\right)$ is the loss modulus.

The study of the storage module $\left(E^{\prime}\right)$ is a determining factor when characterizing the resonance frequencies of a solid. $E^{\prime}$ represents the elastic behavior of the material, which is directly linked to the resonance frequencies of any type of solid. Also, for typical resonant elements of musical instruments, such as membranes, plates or shells, we can express their resonances as [31]

$$
f=\alpha \sqrt{\frac{E^{\prime}}{\rho}}
$$

where the square root of the ratio between $E^{\prime}$ and $\rho$ is equivalent to the longitudinal speed of sound in the solid, and $\alpha$ is a parameter defined by the modal and geometric characteristics of the solid. Variations of $E^{\prime}$ modify the value of each one of the natural frequencies of the system.

In turn, the modulus of losses $E^{\prime \prime}$, is related to the total damping of the system by means of Equation (5) and defines the amount of energy dissipated in each oscillation. The non-elastic or viscous behavior is related to the amount of sound pressure that a resonance will be able to accumulate and the modal decay time. The decay time due to internal damping processes is defined by [32]:

$$
\tau=\frac{1}{\pi f} \frac{E^{\prime}}{E^{\prime \prime}}
$$


Because of their configurability, many manufacturers are investigating the use of composite materials for the manufacture of these instruments. The most common are those using Carbon Fiber Reinforced Epoxy (CFRE) [11,33,34], but others include those involving bio-composites [35,36]. These studies relate the mechanical characteristics of the composite to the sound behavior of different musical instruments, but do not contemplate the direct influence of the processing on the elastic and non-elastic behavior of the vibration.

Since the vibratory behavior and mechanical properties of the material are closely linked [32,37-39], in many cases the processing of the composite offers greater guarantees, such as the laminate of prepregs in an autoclave [40]. But due to the high associated cost, there are numerous studies that propose vacuum bag-only $(\mathrm{VBO})$ processing as an alternative. Previous work has focused on investigating the effects that this can have on porosity, bubbles during curing, and different strategies for mitigating the defects associated with $\mathrm{VBO}$ [41-44], while trying to retain the mechanical properties that the autoclave offers.

It is known that defectology in processing affects the properties of the composite [45]. There are studies linking the appearance of voids during the processing of the composite to the mechanical characteristics of the composite [45,46], and others relating them to material failure [47]. Figure 2 shows the effects of defectology associated with VBO processing [48].

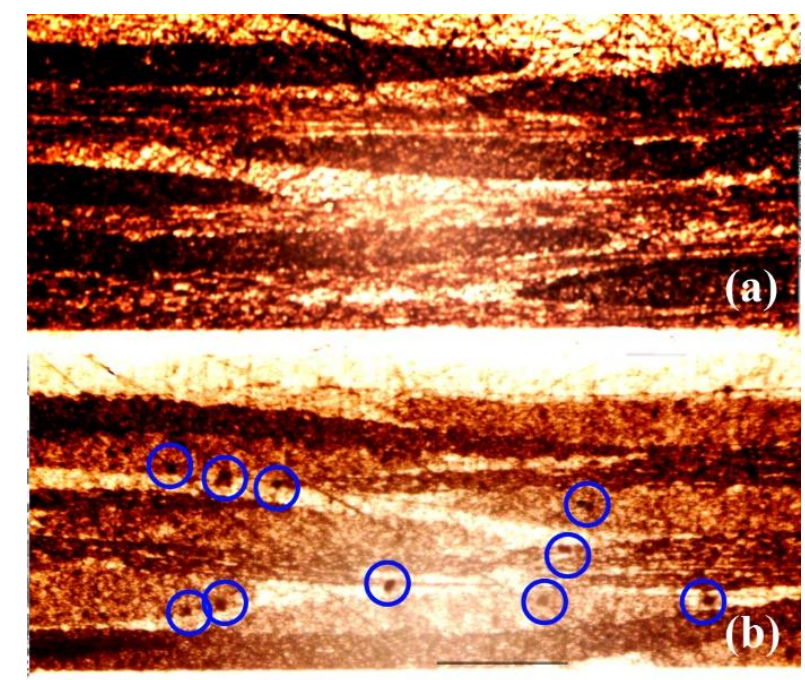

Figure 2. Micrographs of laminates: (a) autoclave processing, and (b) vacuum bag-only (VBO) processing. Blue circles show voids in the VBO laminate.

Studies have also investigated dynamic behavior in composites based on various variables, such as the addition of viscoelastic layers [49] or optimization of damping by characterizing laminate [50]. Since the vibrations of the material are of reduced amplitudes $(<0.1 \mathrm{~mm})$ in the musical instrument manufacturing industry, we can focus the study of the material only on the type of resonances emitted, without addressing aspects such as the failure of the material, either from fatigue or another mechanism.

Accordingly, it is essential to study the direct influence of processing on the modal behavior of the CFRE in so far as different manufacturers can establish criteria for choosing the type of processing. Therefore, this paper aims to evaluate the magnitude of the direct influence of processing by prepreg CFRE, autoclave or vacuum bag-only, on the vibratory characteristics of the composite, considering its sound speed, obtained by its modal behavior, as well as in the decay time result of the damping of the laminate.

\section{Materials and Methods}

For this study two laminates were generated, one by autoclave (A) and the other by vacuum bag-only (VBO) as shown in Figure 3. 


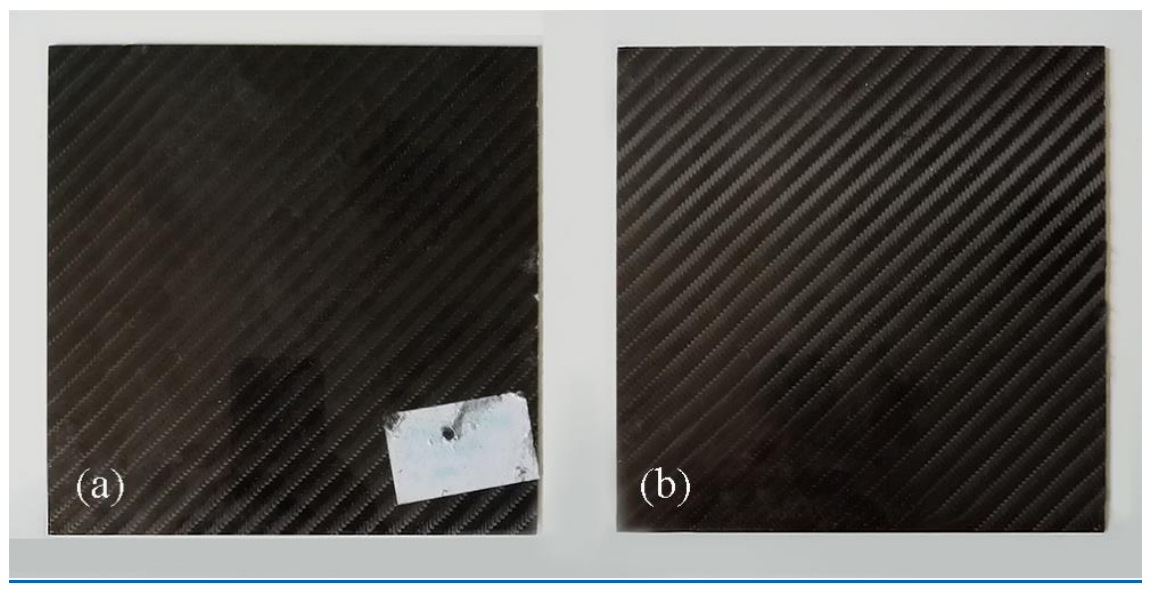

Figure 3. (a) Autoclave and (b) VBO CFRE plates.

Since each solid presents resonances that can be expressed as a direct proportion to the speed of sound of the material that constitutes it, we can extrapolate from the study of the speed of sound to a simple geometry that allows analysis of the material with precision. The geometry used is the rectangular plate, since it allows for obtaining a great number of bending vibration modes.

One way to express the resonances of a rectangular plate is [32]

$$
f_{n}=\frac{0.113 h}{L^{2}} \sqrt{\frac{E}{\rho}}[2 n+1]
$$

where $h$ is the thickness, $L$ is the length of the plate, $E$ is the Young modulus, $\rho$ is the density, and $n$ is the number of nodes.

To be able to cover a range equivalent to three octaves above and below the A3 reference $(440 \mathrm{~Hz})$, the frequency range of the study was focused such that $0<f<2000 \mathrm{~Hz}$. For this, the plate dimensions must be adjusted using Equation (4), which defines the resonances for plates.

The multipurpose CFRE system considered for this investigation was GG280T (Tenax HTA-3k)-DT806R-42 Fabric Laminate manufactured by an external company, (Magma Composites S.L, Alcañiz, Aragón, Spain) using prepreg plies supplied by Delta Preg Composites. DT806 is an epoxy resin with a glass transition temperature (Tg) of approximately $135^{\circ} \mathrm{C}$. GG280T is a $4 / 4$ twill carbon fabric, 3K high strength (HS) carbon fiber reinforcement having a density of $198 \mathrm{~g} / \mathrm{cm}^{2}$. Plates with dimensions of $220 \times 220 \mathrm{~mm}$ were manufactured by the vacuum bag-only and the autoclave method, layering three collinear plies to an approximate total thickness of $1.03 \mathrm{~mm}$. Plate A was cured in an autoclave at $120^{\circ} \mathrm{C}$ for 1 hour, without post-cure. The pressure was $4 \mathrm{~atm}$ for the autoclave plate (A), and atmospheric pressure was used for the $\mathrm{VBO}$ plate. The manufactured plates were afterwards cut down to $30 \times 200 \mathrm{~mm}$ plates, as shown in Figure 4 .

A total of five specimens (dimensions: $200 \mathrm{~mm} \times 30 \mathrm{~mm} \times 1.035 \mathrm{~mm}$ ) were manufactured using three collinear layers, considering that the fiber directions were parallel to the sides of the rectangles that make up the specimen, as shown in the Figure 5.

Properties provided by the manufacturer are shown in Table 1.

In order to characterize the elastic and non-elastic properties of the specimens, a dynamic test was carried out using the vibration procedure under free conditions stipulated in ISO 6721-3 [45], as illustrated in Figure 6. 


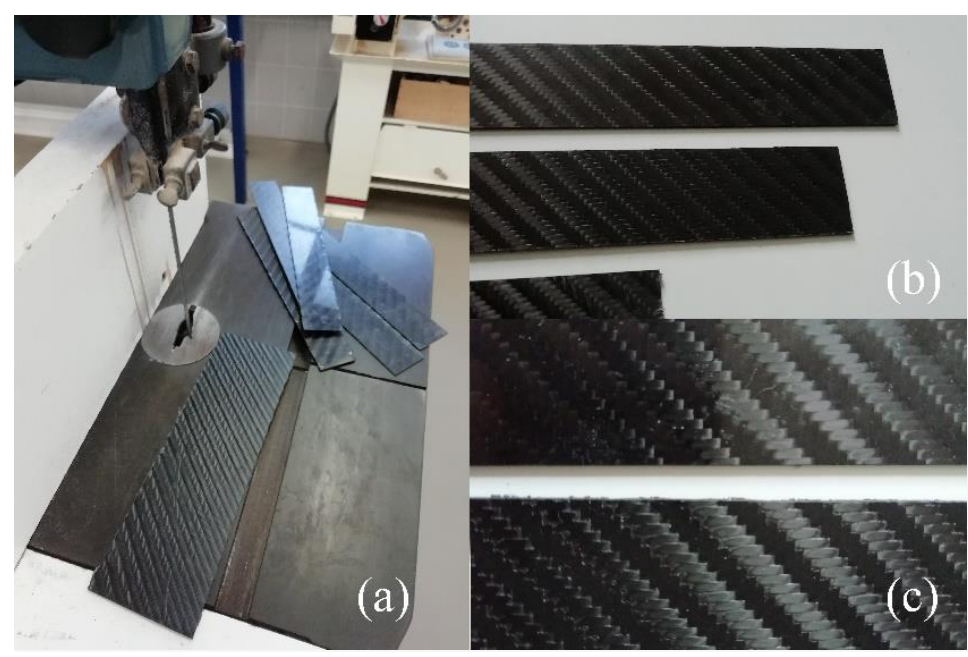

Figure 4. Manufacturing process of CFRE specimens: (a) cutting of $30 \times 200 \mathrm{~mm}$ specimens; (b) finished specimens; and (c) detailed visual comparison of the surface of autoclave and VBO top surfaces.

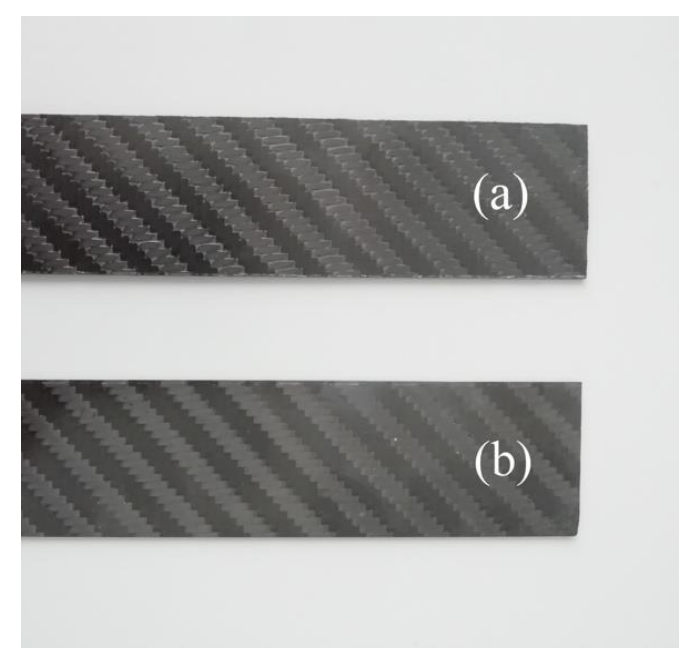

Figure 5. Specimens (a) VBO and (b) autoclave.

Table 1. Static mechanical properties of carbon fiber reinforced epoxy prepreg.

\begin{tabular}{cccccccccc}
\hline & \multicolumn{3}{c}{ Young Modulus (GPa) } & \multicolumn{3}{c}{ Poisson Ratio } & \multicolumn{3}{c}{ Shear Modulus (GPa) } \\
\hline Density $\left(\mathbf{k g} / \mathbf{m}^{\mathbf{3}}\right)$ & $\mathbf{x}$ & $\mathbf{y}$ & $\mathbf{z}$ & $\mathbf{X y}$ & $\mathbf{y z}$ & $\mathbf{x z}$ & $\mathbf{x y}$ & $\mathbf{y z}$ & $\mathbf{x z}$ \\
\hline 1420 & 35.9 & 35.9 & 6.9 & 0.04 & 0.34 & 0.34 & 11.5 & 2.7 & 2.7 \\
\hline
\end{tabular}

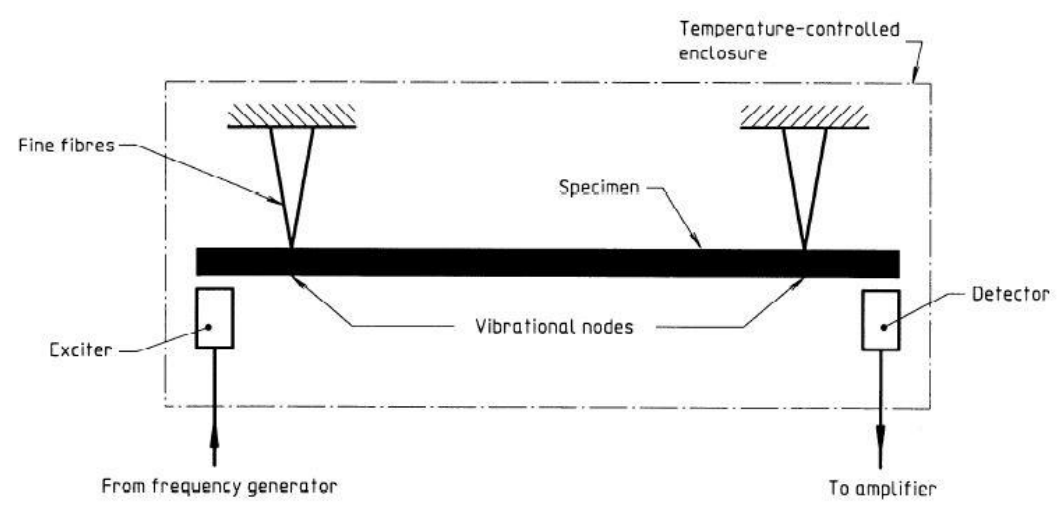

Figure 6. Experimental procedure for identifying resonance frequencies by external excitation [51]. 
In order to obtain experimental resonances for each plate, a wave generator was used to generate a frequency sweep for $0<f<2000 \mathrm{~Hz}$. This sine wave was transferred to an amplifier, which sent the signal to a coil exciting one end of the plate. On the opposite side of the plate, a flat-spectrum microphone was used to capture the sound pressure levels that the plate emits at different frequencies, identifying the resonances of each of the plates.

Once all the resonance frequencies were obtained, the signal decrement was captured. To do this, the plate was subjected to resonance, and the external excitation was cut at the moment of greatest amplitude to let the plate oscillate freely until the oscillation stops. With all captured data, the following calculations were performed.

Vibration modes were obtained as Figure 7 shows, thus obtaining the values of the storage modulus for each of the resonances $\llbracket E^{\prime} \rrbracket f$ with Equation (5). Resonance frequencies for a total of five vibration modes (at pure bending) shown in Figure 8.

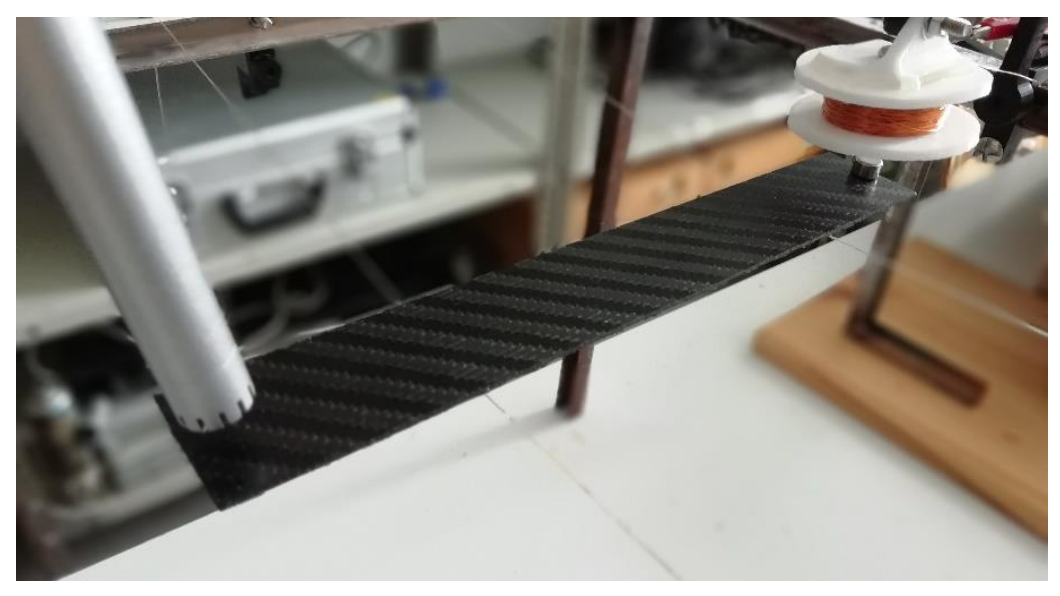

Figure 7. Experimental test for the modal analysis of prepreg CFRE plates.

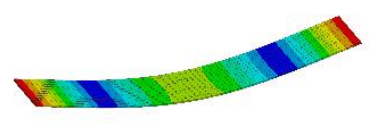

$(2,0)$

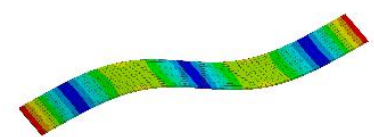

$(3,0)$

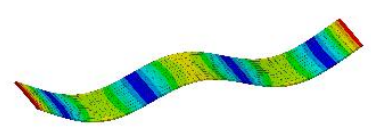

$(4,0)$

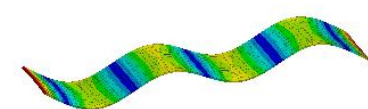

$(5,0)$

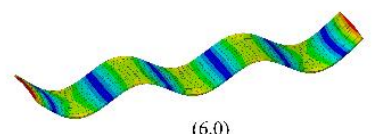

$(6,0)$

Figure 8. Modes obtained through experimentation, following the nomenclature $(m, n)[32]$.

The storage modulus is defined as

$$
E_{f}^{\prime}=\left[\frac{4 \pi(3 \rho)^{1 / 2} l^{2}}{h}\right]^{2}\left(\frac{f_{\mathrm{ri}}}{k_{i}^{2}}\right)^{2}
$$

where $\rho$ is the density, $l$ is the length of the specimen, $h$ is the thickness of the plate, $f_{r i}$ corresponds to the resonance frequency of the $i$-th mode, and $k_{i}^{2}$ is a numerical factor dependent on the $i$-th vibrational mode and the contour conditions of the plate [45].

$E^{\prime}{ }_{f}$ allows the calculation of the speed of sound in the composite, by its relationship to density, using the well-known Equation (6):

$$
c=\sqrt{\frac{E^{\prime}}{\rho}}
$$


In the second part of the study, the composite loss modulus $E^{\prime \prime} f$ was obtained for each of the vibrational modes.

To do this, the signal decrement of the oscillations in free conditions was analyzed for each of the resonances obtained.

The logarithmic decrement is defined as

$$
\delta=\ln \left(\frac{A_{1}}{A_{n}}\right) / N
$$

where $A_{1}$ is the amplitude of the initial oscillation, and is the amplitude of the $n$-th oscillation after the start of the decay.

The loss factor can be expressed as

$$
E_{f}^{\prime \prime}=E_{f}^{\prime} \tan \phi_{f}
$$

where $\phi_{f}$ is the phase or loss angle.

There is a direct relationship between the phase and the loss factor [52]; for $\phi \ll 1$ we can obtain using the following equation:

$$
\tan \phi_{f}=\frac{\delta_{f}}{\pi}
$$

\section{Results and Discussion}

\subsection{Dynamic Characterization}

The results obtained for each of the processed specimens were then analyzed using the procedure described above, as shown in Tables 2 and 3.

Table 2. Average values obtained for CFRE prepreg plates processed by autoclave.

\begin{tabular}{ccccccccc}
\hline $\boldsymbol{\rho}\left(\mathbf{K g} / \mathbf{m}^{3}\right)$ & Mode & $\mathbf{f}(\mathbf{H z})$ & $\mathbf{E}^{\prime}(\mathbf{P a})$ & $\mathbf{E}^{\prime}(\mathbf{P a})$ & $\boldsymbol{\eta}$ & $\boldsymbol{\phi}(\mathbf{R a d})$ & $\boldsymbol{\delta}$ & $\mathbf{c}(\mathbf{m} / \mathbf{s})$ \\
\hline $1.39 \times 10^{3}$ & 2.0 & $1.17 \times 10^{2}$ & $2.73 \times 10^{10}$ & $6.12 \times 10^{7}$ & $2.24 \times 10^{-3}$ & $2.24 \times 10^{-3}$ & $7.05 \times 10^{-3}$ & $4.44 \times 10^{3}$ \\
& 3.0 & $3.52 \times 10^{2}$ & $3.19 \times 10^{10}$ & $7.85 \times 10^{7}$ & $2.46 \times 10^{-3}$ & $2.46 \times 10^{-3}$ & $7.74 \times 10^{-3}$ & $4.80 \times 10^{3}$ \\
& 4.0 & $7.09 \times 10^{2}$ & $3.37 \times 10^{10}$ & $9.18 \times 10^{7}$ & $2.73 \times 10^{-3}$ & $2.73 \times 10^{-3}$ & $8.57 \times 10^{-3}$ & $4.93 \times 10^{3}$ \\
& 5.0 & $1.17 \times 10^{3}$ & $3.36 \times 10^{10}$ & $1.02 \times 10^{8}$ & $3.04 \times 10^{-3}$ & $3.04 \times 10^{-3}$ & $9.55 \times 10^{-3}$ & $4.92 \times 10^{3}$ \\
& 6.0 & $1.69 \times 10^{2}$ & $3.12 \times 10^{10}$ & $1.28 \times 10^{8}$ & $4.10 \times 10^{-3}$ & $4.10 \times 10^{-3}$ & $1.29 \times 10^{-2}$ & $4.74 \times 10^{3}$ \\
\hline
\end{tabular}

Table 3. Average values obtained for CFRE prepreg plates processed by vacuum bag-only.

\begin{tabular}{ccccccccc}
\hline $\boldsymbol{\rho}\left(\mathbf{K g} / \mathbf{m}^{3}\right)$ & Mode & $\mathbf{f}(\mathbf{H z})$ & $\mathbf{E}^{\prime}(\mathbf{P a})$ & $\mathbf{E}^{\prime \prime}(\mathbf{P a})$ & $\boldsymbol{\eta}$ & $\boldsymbol{\phi}(\mathbf{R a d})$ & $\boldsymbol{\delta}$ & $\mathbf{c}(\mathbf{m} / \mathbf{s})$ \\
\hline $1.16 \times 10^{3}$ & 2.0 & $1.15 \times 10^{2}$ & $2.00 \times 10^{10}$ & $5.18 \times 10^{7}$ & $2.59 \times 10^{-3}$ & $2.59 \times 10^{-3}$ & $8.14 \times 10^{-3}$ & $4.15 \times 10^{3}$ \\
& 3.0 & $3.38 \times 10^{2}$ & $2.25 \times 10^{10}$ & $5.60 \times 10^{7}$ & $2.49 \times 10^{-3}$ & $2.49 \times 10^{-3}$ & $7.81 \times 10^{-3}$ & $4.40 \times 10^{3}$ \\
& 4.0 & $6.78 \times 10^{2}$ & $2.37 \times 10^{10}$ & $3.86 \times 10^{8}$ & $1.63 \times 10^{-2}$ & $1.63 \times 10^{-2}$ & $5.12 \times 10^{-2}$ & $4.51 \times 10^{3}$ \\
& 5.0 & $1.11 \times 10^{3}$ & $2.31 \times 10^{10}$ & $3.93 \times 10^{8}$ & $6.60 \times 10^{-2}$ & $6.59 \times 10^{-2}$ & $2.07 \times 10^{-1}$ & $4.46 \times 10^{3}$ \\
& 6.0 & 1716.18 & $2.48 \times 10^{10}$ & $3.91 \times 10^{8}$ & $1.58 \times 10^{-2}$ & $1.58 \times 10^{-2}$ & $4.95 \times 10^{-2}$ & $4.62 \times 10^{3}$ \\
\hline
\end{tabular}

We can see some notable differences between the two types of processing. As Figure 9 shows, the processing change caused a $27 \%$ decrease in the real part of the $E^{\prime}{ }_{f}$ module, which was practically constant for all frequency values. We also observe in the results how the mean values of equivalent density of the plate decrease markedly due to the effects of porosity; the test processed using VBO had a density $16.2 \%$ lower than that processed by $\mathrm{A}$. 


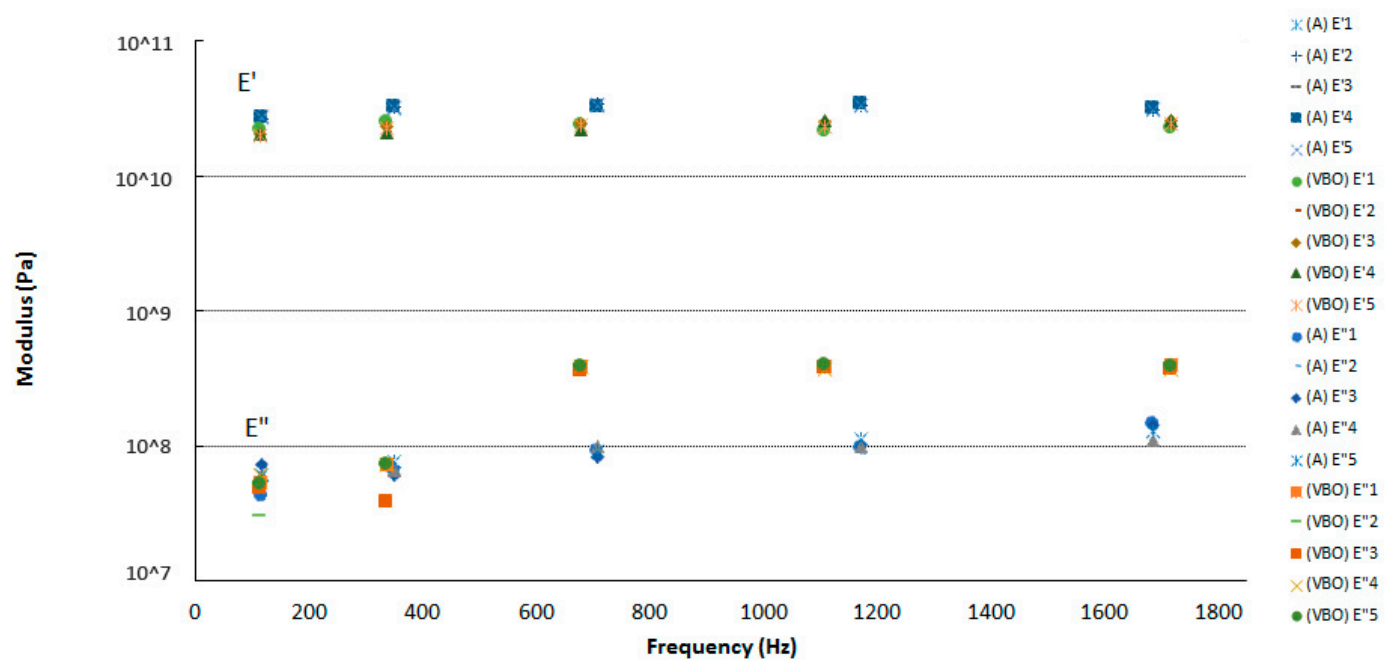

Figure 9. Loss and storage modulus results for CFRE prepregs: A (autoclave) and VBO (vacuum bag-only).

Although both values decrease markedly, we see how the mean frequency values were less than each for both processes, with variations of between $2 \%-6 \%$.

This can be explained by the resulting sound speed of composite $c$ defined by Equation (6) and represented in Figure 10. It is defined as the square root of the ratio between the stiffness and the density of the medium. Because both variables are diminished by porosity, the ratio between them is maintained by mitigating the effect of processing losses, maintaining the wave rate and therefore the values for the resonance frequencies that are proportional to their sound speed [30].

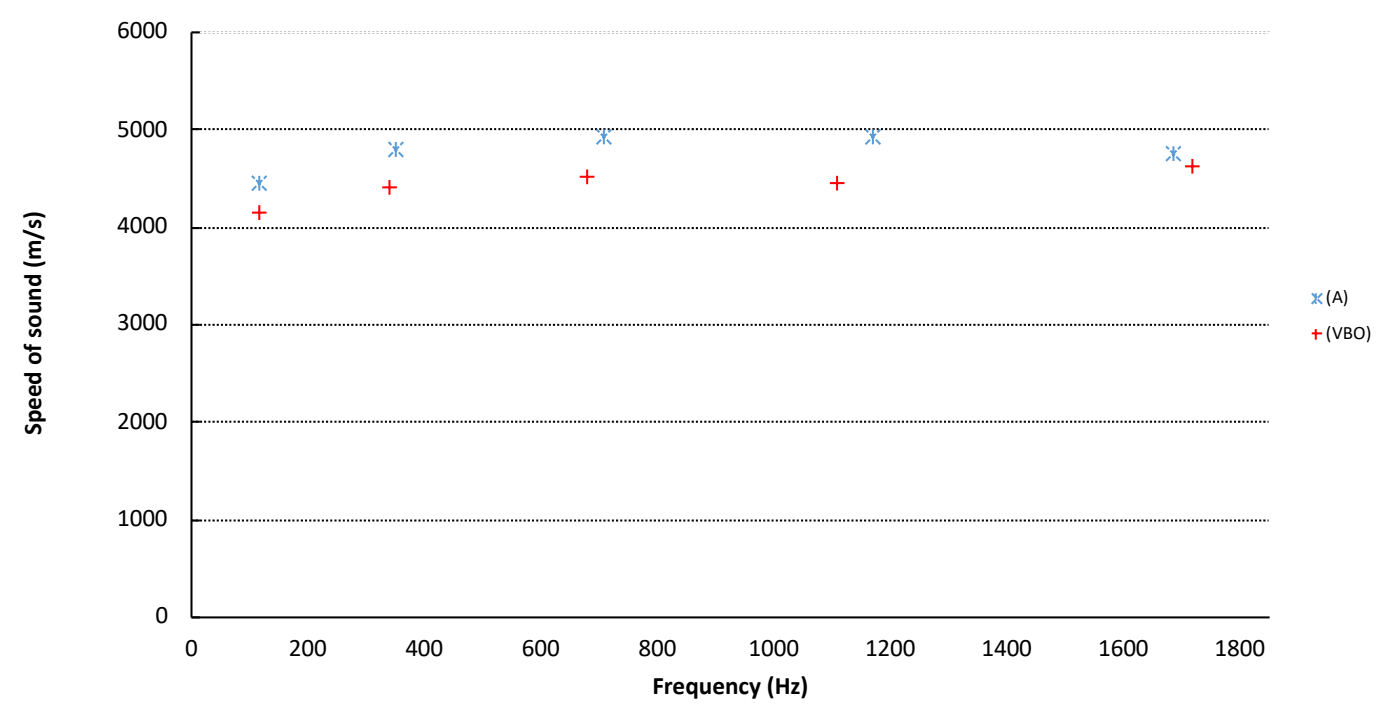

Figure 10. Average sound speed (c) at different frequencies, for CFRE prepregs, processed by A (autoclave) and VBO (vacuum bag-only).

The biggest changes are seen in the non-elastic behavior of the composite. As Figure 9 shows, VBO processing generated a large increase in the loss modulus $E^{\prime \prime}{ }_{f}$ especially in the range $f>400 \mathrm{~Hz}$; for example, 4.2 times higher for vibration mode (4.0) located around $700 \mathrm{~Hz}$.

The increase of the loss modulus against the storage module generated an increase in damping, or loss factor $\eta$, of the composite processed by VBO. As shown, this increase was maximized for $1100 \mathrm{~Hz}$, completely changing the behavior of the material that, in the case of the plate processed by autoclave, exhibited a behavior almost proportional to the frequency. 


\subsection{Effects on The Vibrational Behavior.}

The effect of processing was clearly identifiable in transient analysis Figure 11. As Figure 12 shows, for vibration mode 2.0 with a frequency of $f \cong 115 \mathrm{~Hz}$ the decay times are similar. However, for vibration mode 5.0 with a frequency $f \cong 1150 \mathrm{~Hz}$, damping values were much higher for the plate processed out-of-autoclave, so the duration of the vibration is much shorter.

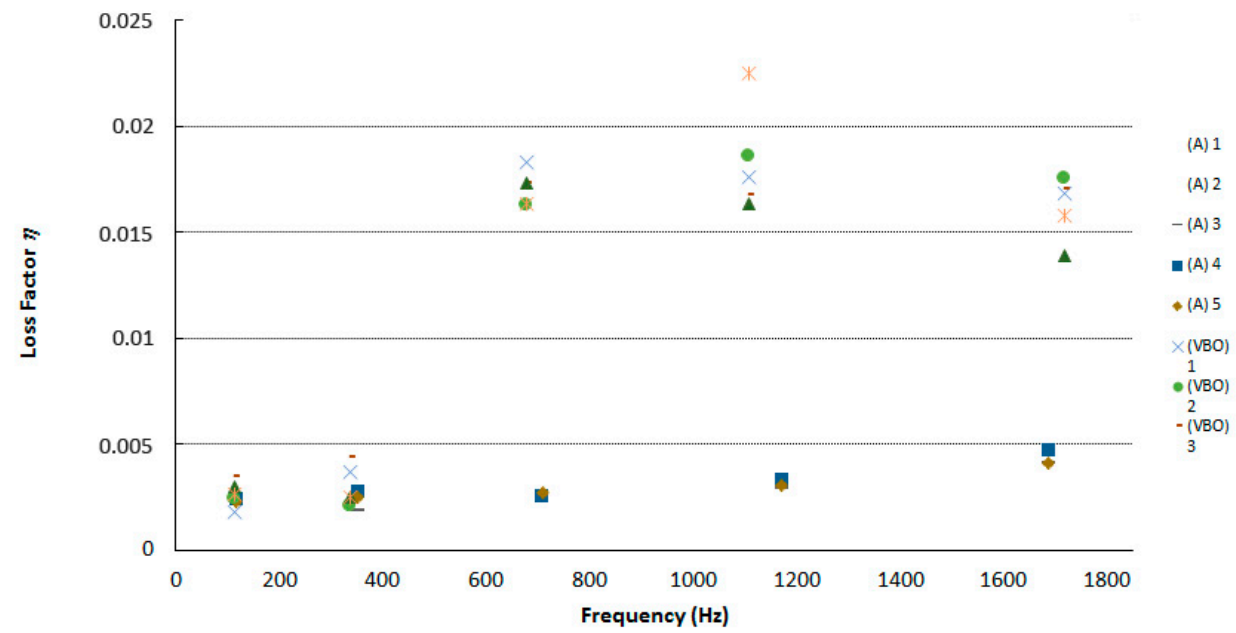

Figure 11. Comparison of the loss factor for CFRE prepregs processed by autoclave and vacuum bag-only.

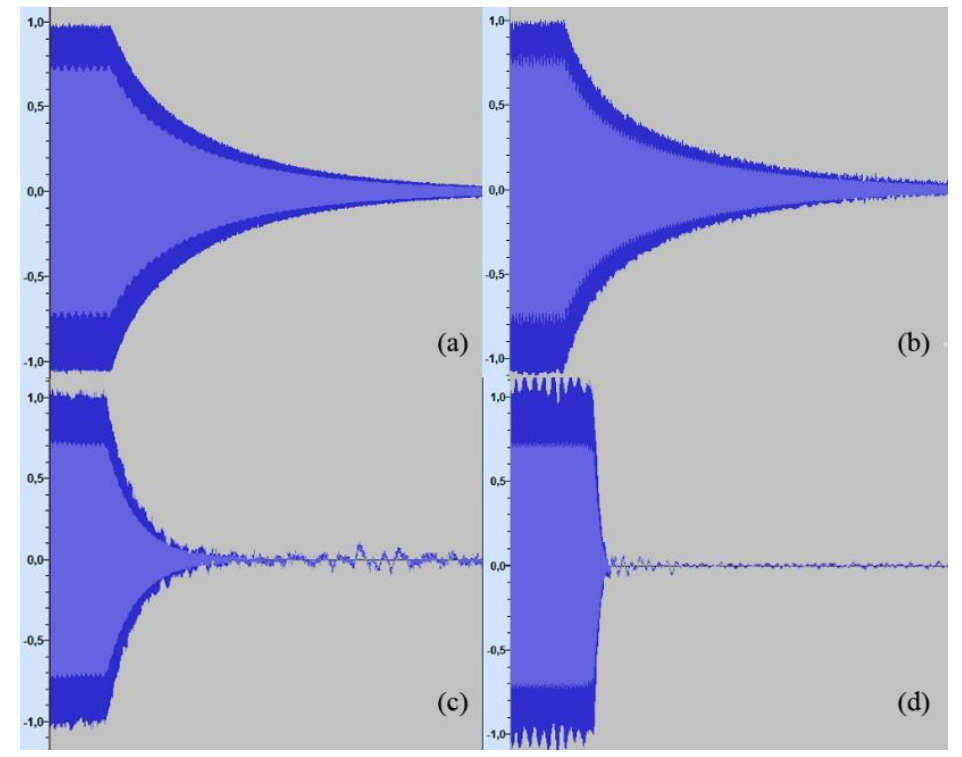

Figure 12. Transient analysis of CFRE plates: (a) Autoclave 2.0 vibrational mode; (b) vacuum bag-only 2.0 vibrational mode; (c) autoclave 5.0 vibrational mode; and (d) vacuum bag-only 5.0 vibrational mode.

The musical instrument manufacturing industry is commonly based on the use of resonances of secondary elements to boost the sound pressure levels of elements such as strings and membranes, but also to emit sound when impacted, as is the case with idiophones.

In both cases, the frequency values for each of the resonances are important, in addition to the damping values, since they define the amount of amplitude that each resonance can accumulate. Higher damping values result in a dissipation of the vibration energy.

As shown in Figure 13, the effect of the different processes of the CFRE is noticeable in the vibratory response of the composite. 


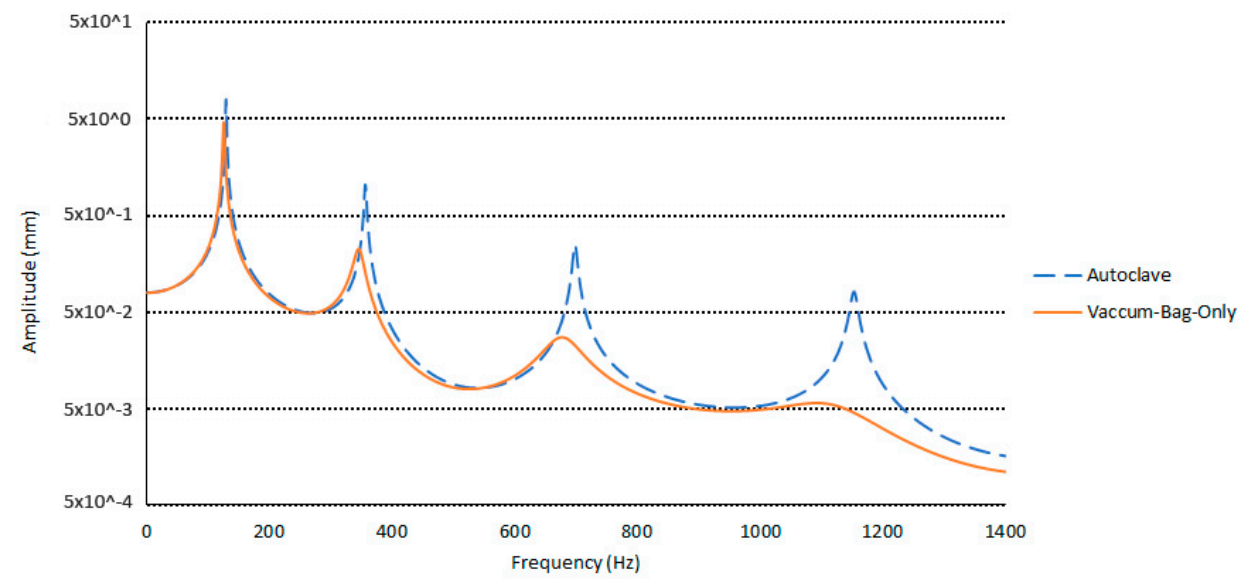

Figure 13. Maximum amplitudes recorded on the different CFRE plates by frequency sweep excitation for $0<f<1400 \mathrm{~Hz}$.

The values of the resonance frequencies were stable due to the similarity of the sound velocities in both processes. The biggest differences were due to the non-elastic behavior of the plates. For low frequency values, where the mechanical differences between the plates are minimal, the resonances were practically equal in amplitude and frequency.

As the frequency increases, the effects of the damping on the VBO plate become more important. This effect is critical near $1000 \mathrm{~Hz}$, where some resonances disappear and their capacity to accumulate amplitude decreases.

\section{Conclusions}

This paper performed a dynamic test to analyze the speed of sound of CFRE prepreg plates processed by two different processes, autoclave and vacuum bag-only. In line with previous studies, we find that processing is an important factor to consider when dynamically characterizing a CFRE prepreg and is undoubtedly a new variable to be taken into account in material design applied to the musical instrument manufacturing industry.

However, although mechanical and physical differences were quantified in the resulting material, due to the stability of the sound speed in the composite, the vacuum bag-only method in CFRE prepregs is shown to be a feasible process for all those applications which require characterizing the elastic behavior and resonance frequencies of a product. Opting for an out-of-autoclave process is guaranteed to be sufficient for the manufacture of musical instruments, if we attend to the values of the resonance frequencies.

The biggest differences were generated at the non-elastic level; there were very significant increases in composite damping, which is something to consider in the design and production process. High damping values mean oscillation energy dissipation, so resonances accumulate less sound pressure. This factor may represent an added difficulty in the musical instrument manufacturing industry, where it is primarily of interest to the maximum accumulation of vibration energy to boost sound pressure levels, and generally materials with low attenuation are suited to this purpose.

In both cases, the knowledge of the influence of processing on the CFRE prepreg allows a more precise characterization of the material. While both processes can ensure stable resonances, due to their similarly elastic behavior, autoclave processing offers composites with lower damping values, improving maximum sound pressure levels. Thus, depending on the frequency range, the use of autoclave processing remains interesting.

Author Contributions: Conceptualization and writing—original draft preparation, M.I.-A.; methodology, M.I.-A. and validation, M.I.-A., F.S.-L. and L.D.-B.; investigation, M.I.-A.; writing-original draft preparation, M.I.-A.; writing-review and editing, F.S.-L., L.D.-B.; supervision, F.S.-L. 
Funding: This research received no external funding.

Conflicts of Interest: The authors declare no conflict of interest.

\section{References}

1. Lee, H.G.; Lee, J. Damping mechanism model for fatigue testing of a full-scale composite wind turbine blade, Part 2: Application of fairing. Compos. Struct. 2018, 202, 1121-1125. [CrossRef]

2. Lee, H.G.; Lee, J. Damping mechanism model for fatigue testing of a full-scale composite wind turbine blade, Part 1: Modeling. Compos. Struct. 2018, 202, 1216-1228. [CrossRef]

3. Henning, F.; Kärger, L.; Dörr, D.; Schirmaier, F.J.; Seuffert, J.; Bernath, A. Fast processing and continuous simulation of automotive structural composite components. Compos. Sci. Technol. 2019, 171, 261-279. [CrossRef]

4. Chen, Y.; Wu, H.; Zhai, J.; Chen, H.; Zhu, Q.; Han, Q. Vibration reduction of the blisk by damping hard coating and its intentional mistuning design. Aerosp. Sci. Technol. 2019, 84, 1049-1058. [CrossRef]

5. Tekin, E.; Kapan, Ö. Composite Manufacturing Data Management in Aerospace Industry. Procedia CIRP 2016, 41, 1039-1042. [CrossRef]

6. Sumi, T.; Ono, T. Classical guitar top board design by finite element method modal analysis based on acoustic measurements of guitars of different quality. Acoust. Sci. Technol. 2008, 29, 381-383. [CrossRef]

7. Torres, J.A.; Boullosa, R.R. Influence of the bridge on the vibrations of the top plate of a classical guitar. Appl. Acoust. 2009, 70, 1371-1377. [CrossRef]

8. Bilbao, S.; Torin, A.; Chatziioannou, V. Numerical modeling of collisions in musical instruments. Acta Acust. United Acust. 2015, 101, 155-173. [CrossRef]

9. Caldersmith, G. Designing a guitar family. Appl. Acoust. 1995, 46, 3-17. [CrossRef]

10. Elejabarrieta, M.J.; Santamaría, C.; Ezcurra, A. Air cavity modes in the resonance box of the guitar: The effect of the sound hole. J. Sound Vib. 2002, 252, 584-590. [CrossRef]

11. Ono, T.; Isomura, D. Acoustic characteristics of carbon fiber-reinforced synthetic wood for musical instrument soundboards. Acoust. Sci. Technol. 2004, 25, 475-477. [CrossRef]

12. Torres, J.A.; Torres-Torres, D. Cambios en la propagación de ondas en una tapa de guitarra debidos al abanico y el puente. Rev. Int. Métodos Numér. Cálc. Diseño Ing. 2015, 31, 228-234. [CrossRef]

13. Nishimura, K.; Nishimura, K. A study on timbre and sound quality of an electric guitar by selection of material around pickup. In Proceedings of the ICSV 23rd International Congress on Sound and Vibration: From Ancient to Modern Acoustics, Athens, Greece, 10-14 July 2016.

14. Paté, A.; Le Carrou, J.L.; Fabre, B. Modal parameter variability in industrial electric guitar making: Manufacturing process, wood variability, and lutherie decisions. Appl. Acoust. 2015, 96, 118-131. [CrossRef]

15. Knott, G.A.; Shin, Y.S.; Chargin, M. A modal analysis of the violin. Finite Elem. Anal. Des. 1989, 5, $269-279$. [CrossRef]

16. Yu, Y.; Jang, I.G.; Kim, I.K.; Kwak, B.M. Nodal line optimization and its application to violin top plate design. J. Sound Vib. 2010, 329, 4785-4796. [CrossRef]

17. Inácio, O.; Antunes, J.; Wright, M.C.M.M. Computational modelling of string-body interaction for the violin family and simulation of wolf notes. J. Sound Vib. 2008, 310, 260-286. [CrossRef]

18. Corradi, R.; Liberatore, A.; Miccoli, S. Experimental modal analysis and finite element modelling of a contemporary violin. In Proceedings of the ICSV 23rd International Congress on Sound and Vibration: From Ancient to Modern Acoustics, Athens, Greece, 10-14 July 2016.

19. Bissinger, G. Modal analysis of a violin octet. J. Acoust. Soc. Am. 2003, 113, 2105-2113. [CrossRef]

20. Berthaut, J.; Ichchou, M.N.; Jézéquel, L. Piano soundboard: Structural behavior, numerical and experimental study in the modal range. Appl. Acoust. 2003, 64, 1113-1136. [CrossRef]

21. Boutillon, X.; Ege, K. Vibroacoustics of the piano soundboard: Reduced models, mobility synthesis, and acoustical radiation regime. J. Sound Vib. 2013, 332, 4261-4279. [CrossRef]

22. Ege, K.; Boutillon, X.; Rébillat, M. Vibroacoustics of the piano soundboard: (Non)linearity and modal properties in the low- and mid-frequency ranges. J. Sound Vib. 2013, 332, 1288-1305. [CrossRef]

23. Ibáñez, M.; Sánchez, F. Material characterization and vibro-acoustic analysis of a Preinpregnated Carbon Fiber reinforced epoxy Drum Shell. In Proceedings of the 20th International Conference on Composite Materials, Copenhagen, Denmark, 19-24 July 2015. 
24. Ibañez, M.; Muñoz, E.; Domenech, L.; Cortés, E.; Sánchez, F.; García, J.A. On the influence of mechanical and processing characterization on the vibro-acoustic response of $1 \mathrm{~cm}$ and preimpregnated composite laminates. In Proceedings of the 13th International Conference on Flow Processes in Composite Materials, Kioto, Japan, 6-9 July 2016.

25. Sathej, G.; Adhikari, R. The eigenspectra of Indian musical drums. J. Acoust. Soc. Am. 2009, 125, 831-838. [CrossRef] [PubMed]

26. Luis and Clark Carbon Fiber Instruments. Available online: https://luisandclark.com (accessed on 12 October 2019).

27. Rasch Drums. Available online: www.raschdrums.com (accessed on 10 October 2019).

28. Boganyi Piano. Available online: http://www.boganyi-piano.com (accessed on 12 October 2019).

29. Klos Carbon Fiber Guitars. Available online: https://klosguitars.com (accessed on 12 October 2019).

30. Nilsson, A.; Liu, B. Vibro-Acoustics; Springer: Berlin/Heidelberg, Germany, 2012; Volume 1, ISBN 9783662478066.

31. Chaigne, A.; Campbell, M. Acoustics of Musical Instruments; Springer: Berlin/Heidelberg, Germany, 2016; ISBN 9781493936779.

32. Fletcher, N.H.; Rossing, T.D. The Physics of Musical Instruments; Springer: New York, NY, USA, 1998.

33. Wu, Z.H.; Li, J.H. Carbon fiber material in musical instrument making. Mater. Des. 2016, 89, 660-664. [CrossRef]

34. Ono, T.; Takahashi, I.; Takasu, Y.; Miura, Y.; Watanabe, U. Acoustic characteristics of wadaiko (traditional Japanese drum) with wood plastic shell. Acoust. Sci. Technol. 2009, 30, 410-416. [CrossRef]

35. Phillips, S.; Lessard, L. Application of natural fiber composites to musical instrument top plates. J. Compos. Mater. 2012, 46, 145-154. [CrossRef]

36. Koruk, H.; Genc, G. Investigation of the acoustic properties of bio luffa fiber and composite materials. Mater. Lett. 2015, 157, 166-168. [CrossRef]

37. Holzweissig, F.; Leissa, A.W. Vibration of Plates. (Nasa Sp-160). VII + 353 S. m. Fig. Washington 1969. Office of Technology Utilization National Aeronautics and Space Administration. Preis brosch. \$3.50. Available online: https://onlinelibrary.wiley.com/doi/abs/10.1002/zamm.19710510331 (accessed on 1 September 2019).

38. Leissa, A.W. Vibration of shells. J. Chem. Inf. Model. 1973, 288, 1689-1699. [CrossRef]

39. Jones, R.M. Mechanics of Composite Materials; Taylor \& Francis: Philadelphia, PA, USA, 1999.

40. Ibáñez, M.; Gimenez, A.; Sanchez, F. Material Characterization and Vibro-Acoustic Analysis of a Preimpregnated Carbon Fiber Drum Shell. In Proceedings of the 20th International Conference on Composite Materials, Copenhagen, Denmark, 19-24 July 2015.

41. Centea, T.; Grunenfelder, L.K.; Nutt, S.R. A review of out-of-autoclave prepregs-Material properties, process phenomena, and manufacturing considerations. Compos. Part. A Appl. Sci. Manuf. 2015, 70, 132-154. [CrossRef]

42. Levy, A.; Kratz, J.; Hubert, P. Air evacuation during vacuum bag only prepreg processing of honeycomb sandwich structures: In-plane air extraction prior to cure. Compos. Part. A Appl. Sci. Manuf. 2015, 68, 365-376. [CrossRef]

43. Kourkoutsaki, T.; Comas-Cardona, S.; Binetruy, C.; Upadhyay, R.K.; Hinterhoelzl, R. The impact of air evacuation on the impregnation time of Out-of-Autoclave prepregs. Compos. Part. A Appl. Sci. Manuf. 2015, 79, 30-42. [CrossRef]

44. Hamill, L.; Centea, T.; Nutt, S. Surface porosity during vacuum bag-only prepreg processing: Causes and mitigation strategies. Compos. Part. A Appl. Sci. Manuf. 2015, 75, 1-10. [CrossRef]

45. Saenz-Castillo, D.; Martín, M.I.; Calvo, S.; Rodriguez-Lence, F.; Güemes, A. Effect of processing parameters and void content on mechanical properties and NDI of thermoplastic composites. Compos. Part. A Appl. Sci. Manuf. 2019, 121, 308-320. [CrossRef]

46. Tai, J.-H.; Kaw, A. Transverse shear modulus of unidirectional composites with voids estimated by the multiple-cells model. Compos. Part. A Appl. Sci. Manuf. 2018, 105, 310-320. [CrossRef]

47. Turteltaub, S.; de Jong, G. Multiscale modeling of the effect of sub-ply voids on the failure of composite materials. Int. J. Solids Struct. 2019, 165, 63-74. [CrossRef]

48. Grunenfelder, L.K.; Nutt, S.R. Void formation in composite prepregs-Effect of dissolved moisture. Compos. Sci. Technol. 2010, 70, 2304-2309. [CrossRef] 
49. Zheng, C.; Liang, S. Preparation and damping properties of medium-temperature co-cured phenolic resin matrix composite structures. Compos. Struct. 2019, 217, 122-129. [CrossRef]

50. Zhang, H.; Ding, X.; Li, H.; Xiong, M. Multi-scale structural topology optimization of free-layer damping structures with damping composite materials. Compos. Struct. 2019, 212, 609-624. [CrossRef]

51. ISO 6721-3 Plastics-Determination of Dynamic Mechanical Properties-Flexural Vibration-Resonance Curve Method. Available online: https://www.iso.org/standard/13169.html (accessed on 1 September 2019).

52. Graesser, E.J.; Wong, C.R. ASTM Special Technical Publication; ASTM: West Conshohocken, PA, USA, 1992; pp. 316-343.

(C) 2019 by the authors. Licensee MDPI, Basel, Switzerland. This article is an open access article distributed under the terms and conditions of the Creative Commons Attribution (CC BY) license (http://creativecommons.org/licenses/by/4.0/). 